\title{
Preserved frontal lobe oxygenation following calcium chloride for treatment of anesthesia-induced hypotension
}

\author{
Carl-Christian Kitchen, Peter Nissen, Niels H. Secher and Henning B. Nielsen*
}

Department of Anesthesia, Rigshospitalet, University of Copenhagen, Copenhagen, Denmark

\section{Edited by:}

Patrice Brassard, Laval University,

Canada

Reviewed by:

Yu-Chieh Tzeng, University of

Otago, Wellington, New Zealand

Samuel J. E. Lucas, University of

Birmingham, UK

*Correspondence:

Henning B. Nielsen, Department of

Anesthesia 2043, Rigshospitalet,

Blegdamsvej 9, 2100

Copenhagen $\varnothing$, Denmark

e-mail: henningbay@hotmail.com

\begin{abstract}
Vasopressor agents may affect cerebral oxygenation $\left(\mathrm{rScO}_{2}\right)$ as determined by near-infrared spectroscopy on the forehead. This case series evaluated the effect of calcium chloride vs. $\alpha$ and $\beta$-adrenergic receptor agonists on $\mathrm{rScO}_{2}$ in patients $(n=47)$ undergoing surgery during i.v. anesthesia. Mean arterial pressure (MAP) and cardiac output (CO) were assessed by Model-flow ${ }^{\circledR}$ and ephedrine $(55 \pm 3$ vs. $74 \pm 9 \mathrm{mmHg}$; $10 \mathrm{mg}, n=9$ ), phenylephrine ( $51 \pm 5 \mathrm{vs} .78 \pm 9 \mathrm{mmHg}, 0.1 \mathrm{mg}, n=11)$, adrenaline ( $53 \pm 3$ vs. $72 \pm 11 \mathrm{mmHg} ; 1-2 \mu \mathrm{g}, n=6$ ), noradrenaline ( $53 \pm 5$ vs. $72 \pm 12 \mathrm{mmHg} ; 2-4 \mu \mathrm{g}, n=$ 11), and calcium chloride ( $49 \pm 7$ vs. $57 \pm 16 \mathrm{mmHg} ; 5 \mathrm{mmol}, n=10$ ) increased MAP (all $P<0.05)$. CO increased with ephedrine $(4.3 \pm 0.9$ vs. $5.3 \pm 1.2, P<0.05)$ and adrenaline $(4.7 \pm 1.2$ vs. $5.9 \pm 1.1 \mathrm{l} / \mathrm{min} ; P=0.07)$ but was not significantly affected by phenylephrine $(3.9 \pm 0.7$ vs. $3.6 \pm 1.0 \mathrm{l} / \mathrm{min})$, noradrenaline $(3.8 \pm 1.2$ vs. $3.7 \pm 0.7 \mathrm{l} / \mathrm{min})$, or calcium chloride $(4.0 \pm 1.4$ vs. $4.1 \pm 1.5 \mathrm{l} / \mathrm{min})$. Following administration of $\beta$-adrenergic agents and calcium chloride $\mathrm{rScO}_{2}$ was preserved while after administration of $\alpha$-adrenergic drugs $\mathrm{rScO}_{2}$ was reduced by app. $2 \%(P<0.05)$. Following $\alpha$-adrenergic drugs to treat anesthesia-induced hypotension tissue oxygenation is reduced while the use of $\beta$-adrenergic agonists and calcium chloride preserve tissue oxygenation.
\end{abstract}

Keywords: brain, blood pressure, cardiac output, NIRS, cerebral oxygenation, cerebral oximetry

\section{INTRODUCTION}

Cerebral autoregulation has a lower limit (Paulson et al., 1990) and following induction of anesthesia blood pressure may decrease to what is considered to be below that level. Accordingly, patients receive intravenous administration of vasopressor agents such as phenylephrine (an $\alpha$-adrenergic receptor agonist) or ephedrine that stimulates both $\alpha$ - and $\beta$-adrenergic receptors. Bolus calcium chloride could also increase blood pressure (Ellender and Skinner, 2008) by an increase in intracellular calcium to increase cardiac stroke volume via an effect on myocytes and vascular resistance via increased contraction of smooth muscles. Also calcium chloride may increase venous return by unloading the splanchnic reservoir. Thus, with administration of calcium chloride cardiac output (CO) increases without affecting heart rate (HR) (Ellender and Skinner, 2008) contrasting ephedrine that has the potential to increase both $\mathrm{HR}$ and $\mathrm{CO}$.

Phenylephrine decreases the near infrared spectroscopy (NIRS) determined frontal lobe oxygenation $\left(\mathrm{rScO}_{2}\right)$ (Brassard et al., 2010, 2014; Nissen et al., 2010; Meng et al., 2011; Foss et al., 2014) related to vasoconstriction in extracranial vasculature rather than to a decrease in cerebral oxygenation (Ogoh et al., 2011, 2014; Sørensen et al., 2012). In this study patients undergoing major abdominal surgery were recruited to evaluate $\mathrm{rScO}_{2}$ following routine administration of vasoactive drugs to treat a drop in blood pressure by induction of anesthesia. We used bolus calcium chloride along with the vasopressor agents phenylephrine, ephedrine, adrenaline or noradrenaline depending on the choice of the anesthesiologist. We tested the hypothesis that administration of ephedrine, adrenaline and calcium chloride to treat anesthesia-induced hypotension would preserve $\mathrm{rScO}_{2}$, while $\mathrm{rScO}_{2}$ would be reduced following administration of drugs that stimulate $\alpha$-adrenergic receptors (phenylephrine and noradrenaline).

\section{METHODS}

In a pilot-like prospective study-design as approved by the regional ethical committee (H-1-2009-107) we included predominantly patients planned for major abdominal surgery. In 47 patients (age $63 \pm 7 \mathrm{yrs}$, height $176 \pm 7 \mathrm{~cm}$, weight $78 \pm 16 \mathrm{~kg} ; 28$ males; mean \pm SD) this selection of cases tested the effect of different vasopressor agents on anesthesia-induced hypotension and $\mathrm{rScO}_{2}$. Most patients were admitted for planned surgery including the liver, pancreas, esophagus, ventricle, or colon. In one case the spleen was the target for surgery and an other patient suffered from a retroperitoneal tumor. Three patients underwent vascular surgery and one patient was in surgery for hydronephrosis. Diabetes requiring insulin and the use of anti-hypertensive medication were considered to contradict inclusion in the evaluated series of patients. An increase in bilirubin was also an exclusion criterion due to the influence of bilirubin on near-infrared light absorption (Madsen et al., 2000).

The patients were exposed to at least $6 \mathrm{~h}$ of fast and orally intake of clear fluids was stopped $2 \mathrm{~h}$ before surgery. Three-lead electrocardiography monitored $\mathrm{HR}$ and pulse oximetry assessed arterial hemoglobin $\mathrm{O}_{2}$ saturation $\left(\mathrm{SpO}_{2}\right)$. A hand vein was used for administration of fluid and anesthetics. According to 
local guidelines, a radial artery catheter (20 gage; $1.1 \mathrm{~mm}$ ) was, after local anesthesia, inserted in the arm with the highest noninvasively determined systolic blood pressure and the catheter was kept patent by isotonic saline $(3 \mathrm{ml} / \mathrm{h})$ through to a transducer (Edwards Life Sciences, Irving, CA, USA) positioned at the level of the heart. For surgery an epidural catheter was placed at Th. 8-10 in the lateral decubitus position and under local anesthesia, lidocaine $(3 \mathrm{ml}, 10 \mathrm{mg} / \mathrm{ml})$ with adrenaline $(5 \mu \mathrm{g} / \mathrm{ml})$ was administered to test for intravascular or intrathecal placement.

A two channel cerebral oximeter (INVOS 5100C, Somanetics, Troy, MI, USA) detected $\mathrm{rScO}_{2}$ that represents hemoglobin oxygen saturation in the tissue beneath the sensor as the ratio between oxygenated and total hemoglobin. As approved by the US Food and Drug Administration (510k-080769), the INVOS 5100C-determined $\mathrm{rScO}_{2}$ is considered a trend monitor of the hemoglobin $\mathrm{O}_{2}$ saturation for skin, scalp, and cortical tissue. With the NIRS-probe applied on the forehead it is assumed that capillaries within the frontal lobe contribute to light absorbance (Madsen and Secher, 1999) but skin, subcutaneous tissue and the scalp blood flow also influences the INVOS-determined $\mathrm{rScO}_{2}$ (Davie and Grocott, 2012). $\mathrm{rScO}_{2}$ was determined at least $2 \mathrm{~cm}$ above the eyebrows to limit an influence from the frontal sinus on $\mathrm{rScO}_{2}$ (Tubbs et al., 2002). Cardiovascular variables including mean arterial pressure (MAP), HR, cardiac stroke volume (SV) and thus $\mathrm{CO}$ were assessed invasively by Model-flow ${ }^{\circledR}$ (Nexfin, B.V, Amsterdam, The Netherlands; Bogert and van Lieshout, 2005).

Anesthesia was induced with propofol $(2 \mathrm{mg} / \mathrm{kg})$ and maintained with propofol $(0.08 \mathrm{mg} / \mathrm{kg} / \mathrm{min})$ and remifentanil $(0.3-$ $0.4 \mu \mathrm{g} / \mathrm{kg} / \mathrm{min})$. For ventilation a Dräger CATO (M32040, Lübeck, Germany) in volume-controlled mode was adjusted to an end-tidal $\mathrm{CO}_{2}$ tension of $4-4.5 \mathrm{kPa}$ and a positive end-expiratory pressure of $5 \mathrm{~cm} \mathrm{H} \mathrm{H}_{2} \mathrm{O}$ was used. When the patient was orally intubated, the inspiratory $\mathrm{O}_{2}$ fraction was set to 0.7 to preserve $\mathrm{rScO}_{2}$ (Rokamp et al., 2014). From induction of anesthesia, including tracheal intubation and until surgical incision, a reduction in MAP to below $60 \mathrm{mmHg}$ was treated with administration calcium chloride ( $5 \mathrm{mmol}$ ) or $\alpha$ - and $\beta$ adrenergic receptors: ephedrine (10 mg), phenylephrine $(0.1-0.2 \mathrm{mg})$, adrenaline (1-2 $\mu \mathrm{g})$, or noradrenaline $(2-4 \mu \mathrm{g})$. No patient received more than one vasoactive agent.

It was estimated that to demonstrate a $10 \pm 1.5 \%$ change in $\mathrm{rScO}_{2}$ (from $70 \%$ to $63 \%$ ) as compared to the level before administration of the drug (alpha 0.05, power $>90 \%$ ) 17 patients was needed in each group. The goal was set to 20 patients to take drop-outs into account, but due to slow enrolment in study it was terminated. The study was conducted as open-label as the drug used depended on the choice of the anesthesiologist.

For comparison of values before and after drug administration a paired $t$-test (two tailed) was used and for comparison between groups and a $t$-test for unpaired data. For evaluation of differences in age, height and weight between groups we used ANOVA with unpaired data and a Tukey-test for post-hoc analysis. Analysis was performed by statistical software (PRISM 6.0 for MacOS; GraphPad software, San Diego, CA, USA) and a $P<0.05$ was considered statistically significant.

\section{RESULTS}

Nine patients were provided with ephedrine to correct anesthesiainduced hypotension, phenylephrine was administered to eleven patients, noradrenaline to eleven patients, six patients received adrenaline, and calcium chloride was administered to ten patients. The five groups of patients were comparable in terms of height and weight but the patients in the adrenaline group were younger than those in the other groups (Table 1).

Bolus calcium chloride maintained $\mathrm{HR}, \mathrm{SV}$, and $\mathrm{CO}$ and, as intended MAP increased (from $49 \pm 7$ to $57 \pm 16 \mathrm{mmHg}$, $P<0.05$ ) (Table 2, Figure 1). The other vasoactive agents also influenced cardiovascular variables: following administration of adrenaline SV tended to increase $(P=0.08)$ and as $\mathrm{HR}$ was maintained $(P=0.71)$ also CO tended to increase (by $25 \%$, $P=0.07)$. Similarly, administration of ephedrine increased CO $(P<0.05)$ due to a non-significant change in $\operatorname{HR}(P=0.26)$ and SV $(P=0.10)$. Both adrenaline and ephedrine increased MAP by $19 \mathrm{mmHg}$. Phenylephrine and noradrenaline maintained $\mathrm{HR}, \mathrm{SV}$, and CO with an increase in MAP by 27 and $20 \mathrm{mmHg}$, respectively.

The effect of vasoactive therapy on the NIRS determined $\mathrm{rScO}_{2}$ are shown in Table 2 and Figure 1. In patients treated with adrenaline and ephedrine $\mathrm{rScO}_{2}$ was not affected significantly and when these data were pooled into one group of patients treated with $\beta$-adrenergic drugs, $\mathrm{rScO}_{2}$ remained statistical unaffected: there was an increase in $\mathrm{rScO}_{2}$ for five patients and for seven patients $\mathrm{rScO}_{2}$ decreased without relation to changes in MAP or CO. After noradrenaline and phenylephrine a small but non-significant reduction in $\mathrm{rScO}_{2}$ was noted for each vasoactive agent. However, with data evaluated as one group ( $\alpha$-adrenergic receptor agonists; noradrenaline and phenylephrine), seven patients with noradrenaline and seven patients with phenylephrine demonstrated lowered $\mathrm{rScO}_{2}$ after drug administration while for only six patients $\mathrm{rScO}_{2}$ increased (Figure 2). For two of these patients $\mathrm{rScO}_{2}$ decreased almost $10 \%$

Table 1 | Patient characteristics in five groups of patients who received vasoactive therapy to treat anesthesia-induced hypotension.

\begin{tabular}{|c|c|c|c|c|c|}
\hline & $\begin{array}{l}\text { Ephedrine } \\
\text { (n=9) }\end{array}$ & $\begin{array}{c}\text { Adrenaline } \\
\qquad(n=6)\end{array}$ & $\begin{array}{l}\text { Phenylephrine } \\
\qquad(n=11)\end{array}$ & $\begin{array}{l}\text { Noradrenaline } \\
\qquad(n=11)\end{array}$ & $\begin{array}{l}\text { Calcium chloride } \\
\qquad(n=10)\end{array}$ \\
\hline Age (yrs) & $67 \pm 3$ & $56 \pm 11^{*}$ & $64 \pm 7$ & $64 \pm 3$ & $60 \pm 9$ \\
\hline Weight (kg) & $84 \pm 18$ & $76 \pm 13$ & $76 \pm 9$ & $76 \pm 16$ & $80 \pm 22$ \\
\hline Height (cm) & $178 \pm 5$ & $174 \pm 6$ & $179 \pm 7$ & $177 \pm 7$ & $172 \pm 7$ \\
\hline
\end{tabular}

Variable are mean $\pm S D .{ }^{*}$ Difference between Ephedrine and Adrenaline; $P<0.05$. 
Table 2 | Cardiovascular variables in five groups of vasoactive therapy to treat anesthesia-induced hypotension.

\begin{tabular}{|c|c|c|c|c|c|c|c|c|c|c|}
\hline & $\begin{array}{c}\text { Adrenaline } \\
\text { before }\end{array}$ & After & $\begin{array}{c}\text { Ephedrine } \\
\text { before }\end{array}$ & After & $\begin{array}{c}\text { Noradrenaline } \\
\text { before }\end{array}$ & After & $\begin{array}{c}\text { Phenylephrine } \\
\text { before }\end{array}$ & After & $\begin{array}{l}\text { Calcium } \\
\text { before }\end{array}$ & After \\
\hline HR (beat/min) & $65 \pm 5$ & $63 \pm 9$ & $60 \pm 9$ & $64 \pm 18$ & $57 \pm 18$ & $58 \pm 19$ & $56 \pm 11$ & $55 \pm 12$ & $61 \pm 14$ & $58 \pm 15$ \\
\hline CO (L/min) & $4.7 \pm 1.1$ & $5.9 \pm 1.1^{*}$ & $4.3 \pm 0.9$ & $5.3 \pm 1.2^{*}$ & $3.8 \pm 1.2$ & $3.7 \pm 0.7$ & $3.9 \pm 0.7$ & $3.6 \pm 1.0$ & $4.0 \pm 1.4$ & $4.1 \pm 1.5$ \\
\hline $\mathrm{MAP}(\mathrm{mmHg})$ & $53 \pm 3$ & $72 \pm 11 *$ & $55 \pm 3$ & $74 \pm 9^{*}$ & $53 \pm 5$ & $72 \pm 12^{*}$ & $51 \pm 5$ & $78 \pm 9^{*}$ & $49 \pm 7$ & $57 \pm 16^{*}$ \\
\hline
\end{tabular}

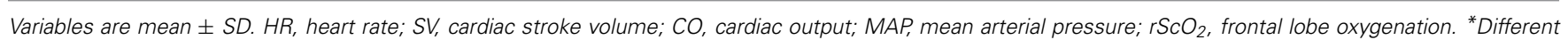

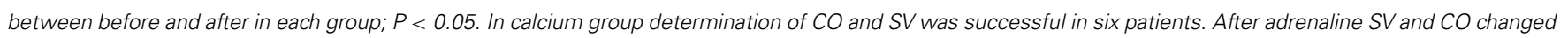
with $P$-values at 0.08 and 0.07 , respectively. Epedrine affected $S V$ at $P=0.10$.

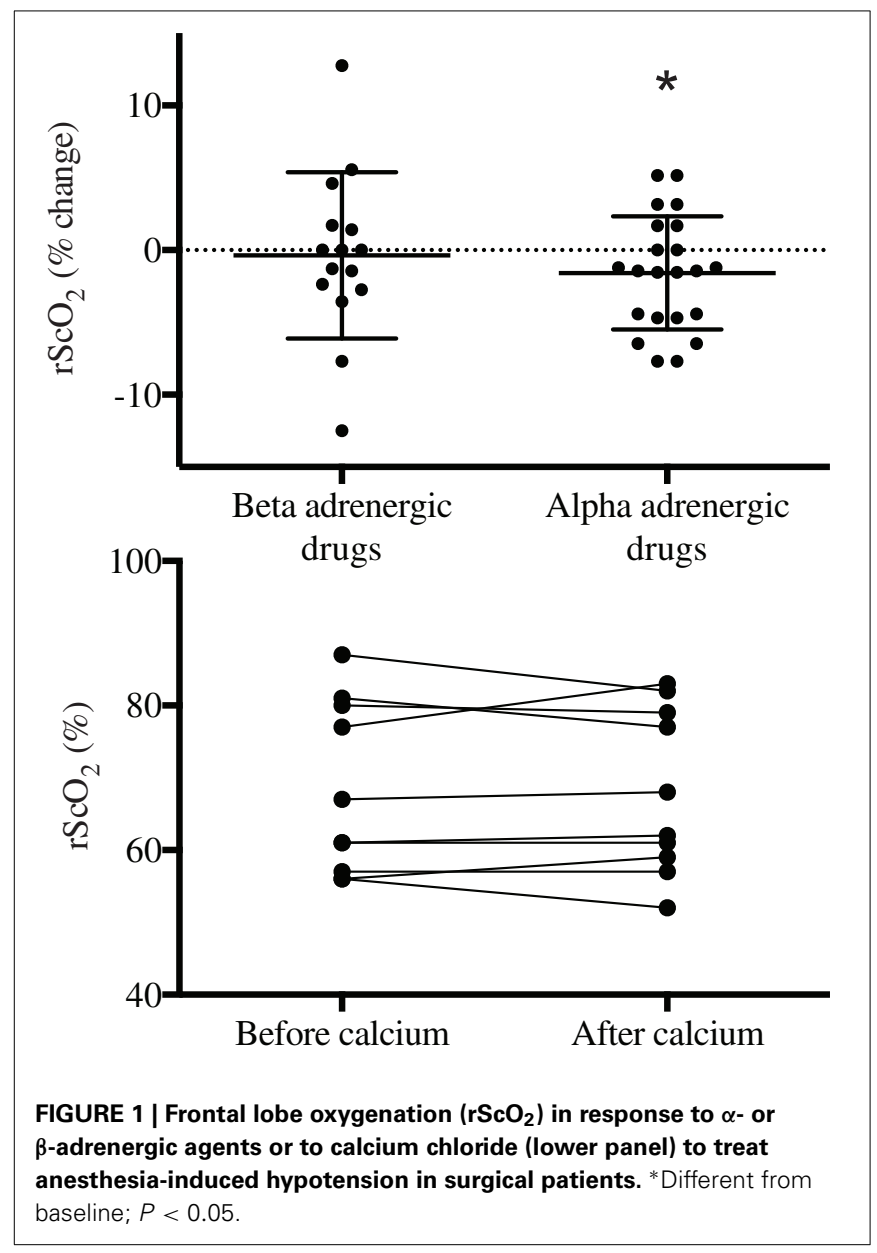

while CO increased $(0.5$ and $2.3 \mathrm{~L} / \mathrm{min})$ and for the whole group of patients ( $\alpha$-adrenergic receptor agonists) $\mathrm{rScO}_{2}$ decreased $2 \%$. After calcium chloride in four patients $\mathrm{rScO}_{2}$ decreased (1-5\%) and while $\mathrm{rScO}_{2}$ was unchanged $(n=2)$ or increased (up to $6 \%$ ) in the other eight patients, $\mathrm{rScO}_{2}$ was not statistical affected by calcium chloride. Correlations between $\mathrm{rScO}_{2}$ and $\mathrm{MAP}$ or $\mathrm{CO}$ were not observed.

\section{DISCUSSION}

This case series of 47 patients confirms that following anesthesiainduced hypotension in elective surgical patients, a vasopressor

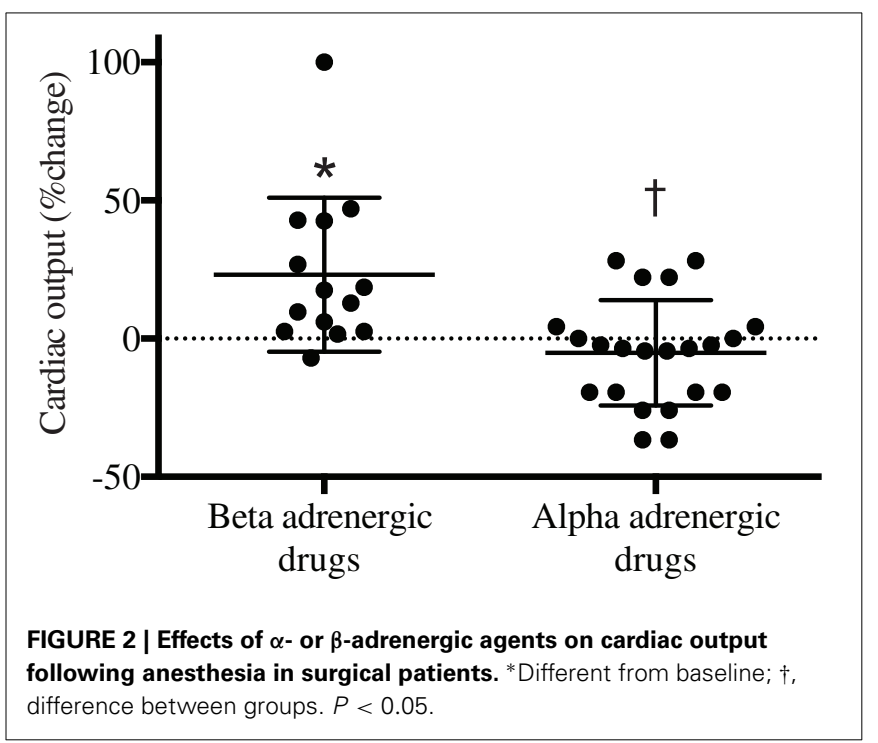

agent including calcium chloride increases MAP. The new finding is that frontal lobe oxygenation $\left(\mathrm{rScO}_{2}\right)$, as determined by near-infrared spectroscopy was not significantly affected following the use of calcium chloride for treatment of anesthesiainduced hypotension. A similar finding was observed with the use of ephedrine, phenylephrine, adrenaline, and noradrenaline as $\mathrm{rScO}_{2}$ remained at levels similar to those established before drug administration. However, when data from patients treated with $\alpha$-adrenergic receptor agonists (phenylephrine and noradrenaline) were pooled into one group and patients treated with $\beta$-adrenergic drugs (adrenaline or ephedrine) were sampled in an other group, $\mathrm{rScO}_{2}$ decreased $2 \%$ after $\alpha$-adrenergic drug administration but remained unaffected with administration of $\beta$-adrenergic stimulating drugs. This observation supports results obtained in patients (Nissen et al., 2010; Meng et al., 2011; Brassard et al., 2014) and healthy awake subjects (Brassard et al., 2010). Although a $2 \%$ reduction in $\mathrm{rScO}_{2}$ seems small, the change is in the magnitude as induced by hyperventilation that lowers arterial $\mathrm{CO}_{2}$ partial pressure with development of presyncopal symptoms (Madsen and Secher, 1999). Also Thomas et al. (2009) report $\sim 6 \%$ drop in cerebral oxygenation at presyncope.

Why $\mathrm{rScO}_{2}$ is reduced after $\alpha$-adrenergic drugs and not after administration of $\beta$-adrenergic-therapy and calcium chloride 
remains unclear. In patients with intact cerebral autoregulation, the decrease in $\mathrm{rScO}_{2}$ after phenylephrine and noradrenalin administration is associated with concordant reduction in $\mathrm{CO}$, whereas $\mathrm{rScO}_{2}$ remains unchanged when $\mathrm{CO}$ was maintained with ephedrine (Meng et al., 2011). This observation supports that changes in $\mathrm{CO}$, independently of arterial pressure, affect cerebral hemodynamics (Ogoh et al., 2005). Cerebral arteries are abundantly innervated by sympathetic fibers (Sandor, 1999) and the decrease in $\mathrm{rScO}_{2}$ after administration of $\alpha$-adrenergic drugs could be by direct $\alpha$-receptormediated cerebral vasoconstriction. An influence of cutaneous vasoconstriction beneath the NIRS optode, however has to be considered (Davie and Grocott, 2012; Sørensen et al., 2012).

The increase in MAP by vasoactive therapy was expected and the use of bolus calcium chloride also increased MAP even in patients without a suspected reduction in plasma ionized calcium. Indication for the use of calcium chloride is more clear after the use of blood products containing citrate that may lead to hypocalcemia (Jawan et al., 2003) and hemodynamic instability (Marquez et al., 1986). Thus, calcium chloride restores the levels of ionized calcium in blood and in turn also MAP.

Despite the effect of vasoactive agents on MAP was similar with the use of different drugs, the rise in pressure was achieved differently. Both ephedrine and adrenaline increased CO but such an effect was absent after administration of phenylephrine or noradrenaline. When data from patients treated with noradrenaline and phenylephrine were pooled into one group, CO was reduced in several patients (Figure 2): the eight lowest points with a decrease in $\mathrm{CO}$ by up to app. $50 \%$ represent four patients treated with phenylephrine and four patients treated with noradrenaline. After calcium chloride $\mathrm{CO}$ was unchanged and there was a trend towards a reduced HR $(P=0.16)$. For most of the patients treated with $\beta$-adrenergic agonists, $\mathrm{CO}$ increases by unloading of the splanchnic reservoir (Cannesson et al., 2012). An increase in CO may be important to override potential vasoconstriction in cutaneous and subcutaneous vessels following the use of vasoactive therapy. Considering that microvascular circulation influences wound healing, we consider that vasoactive drugs with significant vasoconstrictive capacity should be avoided both during and after surgery.

The use of calcium chloride to restore MAP is safe and in terms of the effect on $\mathrm{rScO}_{2}$ this study is unable to promote one vasoactive drug over an other. The data do suggest that the use of a vasopressor agent with combined $\alpha$ - and $\beta$-adrenergic agonistic capacity appears to be favorable to restore MAP following anesthesia-induced hypotension. Results from a randomized double-blinded clinical trial are needed before a general recommendation to use combined $\alpha$ - and $\beta$-adrenergic drugs or calcium chloride for treatment of anesthesia-induced hypotension is substantiated.

\section{ACKNOWLEDGMENTS}

Henning Bay Nielsen was funded by Rigshospitalet Research fund and the Danish Agency for Science Technology and Innovation (271-08-0857).

\section{REFERENCES}

Bogert, L. W., and van Lieshout, J. J. (2005). Non-invasive pulsatile arterial pressure and stroke volume changes from the human finger. Exp. Physiol. 90, 437-446. doi: 10.1113/expphysiol.2005.030262

Brassard, P., Pelletier, C., Martin, M., Gagné, N., Poirier, P., Ainslie, P. N., et al. (2014). Influence of norepinephrine and phenylephrine on frontal lobe oxygenation during cardiopulmonary bypass in patients with diabetes. J. Cardiothorac. Vasc. Anesth. 28, 608-617. doi: 10.1053/j.jvca.2013. 09.006

Brassard, P., Seifert, T., Wissenbrg, M., Jensen, P. M., Hansen, C. K., and Secher, N. H. (2010). Phenylephrine decreases frontal lobe oxygenation at rest but not during moderately intense exercise. J. Appl. Physiol. 108, 1472-1478. doi: 10.1152/japplphysiol.01206.2009

Cannesson, M., Jian, Z., Chen, G., Vu, T. Q., and Hatib, F. (2012). Effects of phenylephrine on cardiac output and venous return depend on the position of the heart on the Frank-Starling relationship. J. Appl. Physiol. 113, 281-289. doi: 10.1152/japplphysiol.00126.2012

Davie, S. N., and Grocott, H. P. (2012). Impact of extracranial contamination on regional cerebral oxygen saturation: a comparison of three cerebral oximetry technologies. Anesthesiology 116, 834-840. doi: 10.1097/ALN.0b013e318 $24 \mathrm{c} 00 \mathrm{~d} 7$

Ellender, T. J., and Skinner, J. C. (2008). The use of vasopressors and inotropes in the emergency medical treatment of shock. Emerg. Med. Clin. North Am. 26, 759-786. doi: 10.1016/j.emc.2008.04.001

Foss, V. T., Christensen, R., Rokamp, K. Z., Nissen, P., Secher, N. H., and Nielsen, H. B. (2014). Effect of phenylephrine vs. ephedrine on frontal lobe oxygenation during caesarean section with spinal anesthesia: an open label randomized controlled trial. Front. Physiol. 5:81. doi: 10.3389/fphys.2014. 00081

Jawan, B., de Villa, V., Luk, H. N., Chen, Y. S., Chiang, Y. C., Wang, C. C., et al. (2003). Ionized calcium changes during living-donor liver transplantation in patients with and without administration of bloodbank products. Trans. Int. 16, 510-514. doi: 10.1111/j.1432-2277.2003. tb00340.x

Madsen, P. L., and Secher, N. H. (1999). Near-infrared oximetry of the brain. Prog. Neurobiol. 58, 541-560.

Madsen, P. L., Skak, C., Rasmussen, A., and Secher, N. H. (2000). Interference of cerebral near-infrared oximetry in patients with icterus. Anesth. Analg. 90, 489-493. doi: 10.1097/00000539-200002000-00046

Marquez, J., Martin, D., Virji, M. A., Kang, Y. G., Warty, V. S., Shaw, B. Jr., et al. (1986). Cardiovascular depression secondary to ionic hypocalcemia during hepatic transplantation in humans. Anesthesiology 65, $457-461$.

Meng, L., Cannesson, M., Alexander, B. S., Yu, Z., Kain, Z. N., Cerussi, A. E., et al. (2011). Effect of phenylephrine and ephedrine bolus treatment on cerebral oxygenation in anaesthetized patients. Br. J. Anaesth. 107, 209-217. doi: 10.1093/bja/aer150

Nissen, P., Brassard, P., Jorgensen, T. B., and Secher, N. H. (2010). Phenylephrine but not Ephedrine reduces frontal lobe oxygenation following anesthesiainduced hypotension. Neurocrit. Care 12, 17-23. doi: 10.1007/s12028-0099313-x

Ogoh, S., Brothers, R. M., Barnes, Q., Eubank, W. L., Hawkins, M. N., Purkayastha, S., et al. (2005). The effect of changes in cardiac output on middle cerebral artery mean blood velocity at rest and during exercise. J. Physiol. 569, 697-704. doi: 10.1113/jphysiol.2005. 095836

Ogoh, S., Sato, K., Fisher, J. P., Seifert, T., Overgaard, M., and Secher, N. H. (2011). The effect of phenylephrine on arterial and venous cerebral blood flow in healthy subjects. Clin. Physiol. Funct. Imaging 31, 445-451. doi: 10.1111/j.1475097X.2011.01040.x

Ogoh, S., Sato, K., Okazaki, K., Miyamoto, T., Secher, F., Sørensen, H., et al. (2014). A decrease in spatially resolved near-infrared spectroscopydetermined frontal lobe tissue oxygenation by phenylephrine reflects reduced skin blood flow. Anesth. Analg. 118, 823-829. doi: 10.1213/ANE.000000000 0000145

Paulson, O. B., Strandgaard, S., and Edvinsson, L. (1990). Cerebral autoregulation. Cerebrovasc. Brain Metab. Rev. 2, 161-192.

Rokamp, K. Z., Secher, N. H., Eiberg, J., Lønn, L., and Nielsen, H. B. (2014). O2 supplementation to secure the near-infrared spectroscopy determined brain and 
muscle oxygenation in vascular surgical patients: a presentation of 100 cases. Front. Physiol. 5:66. doi: 10.3389/fphys.2014.00066

Sandor, P. (1999). Nervous control of the cerebrovascular system: doubts and facts. Neurochem. Int. 35, 237-259.

Sørensen, H., Secher, N. H., Siebenmann, C., Nielsen, H. B., Kohl-Bareis, M., Lundby, C., et al. (2012). Cutaneous vasoconstriction affects spectroscopy-determined cerebral oxygen saturation during administration of norepinephrine. Anesthesiology 117, 263-270. doi: 10.1097/ALN.0b013e 3182605afe

Thomas, K. N., Cotter, J. D., Galvin, S. D., Williams, M. J., Willie, C. K., and Ainslie, P. N. (2009). Initial orthostatic hypotension is unrelated to orthostatic tolerance in healthy young subjects. J. Appl. Physiol. 107, 506-517. doi: 10.1152/japplphysiol.91650.2008

Tubbs, R. S., Elton, S., Salter, G., Blount, J. P., Grabb, P. A., and Oakes, W. J. (2002). Superficial surgical landmarks for the frontal sinus. J. Neurosurg. 96, 320-322. doi: $10.3171 /$ jns.2002.96.2.0320
Conflict of Interest Statement: The authors declare that the research was conducted in the absence of any commercial or financial relationships that could be construed as a potential conflict of interest.

Received: 04 July 2014; accepted: 01 October 2014; published online: 22 October 2014 Citation: Kitchen C-C, Nissen P, Secher NH and Nielsen HB (2014) Preserved frontal lobe oxygenation following calcium chloride for treatment of anesthesia-induced hypotension. Front. Physiol. 5:407. doi: 10.3389/fphys.2014.00407

This article was submitted to Integrative Physiology, a section of the journal Frontiers in Physiology.

Copyright (C) 2014 Kitchen, Nissen, Secher and Nielsen. This is an open-access article distributed under the terms of the Creative Commons Attribution License (CC BY). The use, distribution or reproduction in other forums is permitted, provided the original author(s) or licensor are credited and that the original publication in this journal is cited, in accordance with accepted academic practice. No use, distribution or reproduction is permitted which does not comply with these terms. 